\title{
PROCESSOS AVALIATIVOS E FORMAÇÃO DOCENTE NA PERSPECTIVA INTERCULTURAL CRÍTICA DE EDUCAÇÃO
}

\author{
Sônia Maria Vieira da Silva ${ }^{\mathrm{i}}$
}

Nesse trabalho, está em jogo os processos de aprendizagem e de avaliação tendo como ponto de partida a análise de aspectos teórico-práticos sobre a experiência discente e docente, no âmbito da educação. Faz sentido considerarmos algumas confluências para defender a diversidade de propostas de avaliação adotadas como atalhos, como um exemplo de superação das desigualdades sócio-educacionais. Desse modo, com o intuito de admitir o lugar de importância dos exercícios que emergiram de algumas conformações experimentadas no cotidiano, nas idas e vindas como professoras e ao mesmo tempo como estudantes, é que a revisão das perspectivas que nos habitam - sujeitos da educação -, passou a ser imperativo.

A perspectiva intercultural crítica de educação, se assenta na concepção de uma educação emancipatória que, como afirmou Vera Candau (2012b, p. 48), tem as ações fundamentais de desconstruir preconceitos e discriminações, articular igualdade e diferença, resgatar no nível individual e coletivo "processos de construção das nossas identidades culturais". A perspectiva intercultural crítica de educação não invisibiliza os conflitos inerentes às diferenças que habitam os espaços de aprendizagem, muito pelo contrário, os enfrenta, porque compreende que o processo de ensinar e de aprender não se faz com o (as) estudante idealizado, mais sim com alunos e alunas reais. Quando percebemos a avaliação a partir dessa perspectiva concebemos o processo como permanente.

Ao rememorar as vivências discentes e as especificidades da avaliação na escola (níveis fundamental e médio), a insegurança aparece em destaque. Ganhou relevo as situações de viver com o medo de "fazer prova", passar pelos "testes" periódicos. O que se aparece, ao mesmo tempo, como pista para entender como construímos, nós, os discentes que se tornam docentes, os valores aí incutidos. Com as pesquisas que temos desenvolvido com base na cooperação entre profissionais incomodadas (os) com as hierarquias estabelecidas nesse ambiente, tem sido possível constatar que as expressões de insegurança levam a uma descrença no desenvolvimento de habilidades tais como a leitura e a escrita.

A perspectiva intercultural crítica de educação, visa "promover experiências de interação sistemática" com distintas formas e modos de concepção da vida. Subjacente a esta concepção emancipatória, está a necessidade da reconstrução de uma educação que não se volte prioritariamente para "[...] algumas situações e/ou atividades realizadas em momentos 
específicos, nem focalizar sua atenção exclusivamente em determinados grupos sociais" (CANDAU, 2012b, p. 48). Ou seja, atividades pontuais ou folclóricas que para Carlos Skliar (2003, p. 4) não passam de uma banalização do outro, na medida em que não reconhece a diferença cultural dentro do espaço escolar. Ao retornarmos aos achados de Candau (Ibidem) é possível acreditar que a perspectiva intercultural crítica nasce com base em práticas que adotam como fundamento, a relação educação e cultura visando promover o fortalecimento de indivíduos ou grupos sociais que "[...] historicamente tiveram menos poder na sociedade [...], menores possibilidades de influir nas decisões e nos processos coletivos" (CANDAU, 2012b, p. 49-50).

A profissão docente nos convida a considerar as chances desses fios influenciarem outras intervenções pedagógicas. Quando mapeamos a produção já existente sobre avaliação nos últimos anos, o que se observa é a urgência de trazer à tona resultados de experiências que possam facilitar o reconhecimento do trabalho pedagógico como uma aposta na emancipação social. Durante o exercício da nossa profissão como professoras das redes públicas e também profissionais inseridas em projetos desenvolvidos em instituições privadas, identificamos nuances das armadilhas que, facilmente, nos levam a reproduzir os modelos de avaliar na perspectiva da meritocracia, da exclusão e do não reconhecimento da diversidade de desempenho, por assim dizer. São ações estigmatizadoras que garantem a degenerescência dessas identidades docentes e discentes - e que concorrem com práticas mais significativas para esses atores na instituição.

$\mathrm{Na}$ dança das cadeiras e, em termos teórico-metodológicos, acreditamos na possibilidade de "reinventar a escola" e, a partir desse quadro propositivo, ganha importância o processo de desconstrução das formas de conceber o outro da educação que nos aprisionam a um modelo hegemônico de educar. No lugar de se admitir a emancipação nota-se o apelo aos encaixes e ajustes educacionais. São padrões cujo resultado é a hierarquização desses contingentes. Ao examinar, aspectos que dizem respeito às diferenças culturais e práticas pedagógicas, Candau (2012b, p. 92), assinala:

[...] são recorrentes [...] as evidências empíricas da dificuldade de se lidar nas práticas educativas com as diversas manifestações da diferença: de gênero, étnicas, de orientação sexual, geracional, sensório-motoras, cognitivas, entre outras. 'Aqui são todos iguais' é muito frequente os/as professores/as afirmarem quando se pergunta como lidam com as diferenças, para significar que os dispositivos pedagógicos mobilizados são padronizados e uniformes. 
Essas manifestações de igualdade nada mais são do que uma visão deturpada do que é lidar com as diferenças, pois ela implica em invisibilizar aquele(a) considerado(a) fora do padrão, do modelo ideal. E essa forma de pensar também nos constitui.

\section{A reprodução de assimetrias como resultado}

No Brasil, autores tais como Cipriano Luckesi, Ana Maria Saul, Jussara Hoffmann, (desde os anos de 1980), Maria Teresa Esteban, Celso Vasconcellos, Regina Leite Garcia dentre outros mais recentes -, tem se debruçado sobre o tema da avaliação. Em um curso de graduação em Pedagogia, estão presentes como referência obrigatória no currículo proposto pelo projeto político-pedagógico da unidade. Ao iniciarmos esse trabalho, afirmamos que viver o medo dos "exames", revelou o quanto a insegurança manifesta pode ser consequência de uma proposta de formação pautada na exclusão.

Pensando com Cipriano Luckesi (2000, p. 169) nota-se que ao fazer uso de provas e de exames a comunidade escolar está preocupada em responder a uma exigência da sociedade burguesa, que estabelece como prioridade a aferição do aprendizado de determinados conteúdos e que se constitui pela marginalização de grande parte dos elementos da sociedade. Estudos recentes já mencionam os caminhos pelos quais uma instituição se torna referência para as famílias que buscam a tão propagada qualidade de ensino. Daí pode-se examinar os motivos de jubilamento de estudantes em inúmeras instituições que oferecem educação básica (níveis fundamental e médio) e que, na maioria das vezes, organizam um currículo para atender a um segmento específico em detrimento de outros.

A exclusão e marginalização são acionadas a partir da medição e comprovação da capacidade, do domínio ou não de uma série de conhecimentos legitimados como saberes escolares, do aprovar e do reprovar. Os instrumentos de medição mais tradicionais indicam que é preciso avaliar, julgar para separar os segmentos da sociedade; impõem uma forma de avaliação que prima pela hierarquização dos saberes e dos sujeitos, e que se conforma em uma prática que ameaça que não acolhe e, portanto, enraizada nos rituais de seleção/invisibilização. Até aqui, acompanhando a produção nesse campo temático, vimos que para fomentarmos novos espaços dialógicos é preciso enfrentar algumas indagações sobre as perspectivas de futuro dessa conjuntura. Em todos os pontos do globo, nos países vitimados pela violência do Estados e do empresariado e que, dependem do grande capital, o modelo socioeconômico se funda em uma política neoliberal revitalizada a cada período de crise social e econômica. 
A privatização, a globalização, o livre comércio, a entrada de multinacionais, o protecionismo, o capital especulativo e outros princípios que, para os que defendem esta ideologia, promovem o desenvolvimento e o crescimento econômico, tem beneficiado os detentores dos meios de produção, as empresas multinacionais e as grandes potências econômicas. Como consequência, os países fora do eixo das grandes potências, e/ou delas dependentes, tentam se aproximar da utopia desse ideário, reproduzindo uma política econômica, cujos efeitos impactam em todas as esferas, principalmente na educação formal.

Para Ángel Barriga (2003, p. 51), a materialização da política educativa de corte liberal está ancorada no falso principio didático, onde a concepção hegemônica é a de que quanto melhor o sistema de exame, melhor será o sistema de ensino. Barriga afirma que a política educacional, da mesma orientação, tem como fundamentos a qualidade da educação, a eficiência e a eficácia do sistema educativo, e por isso produz um alargamento do vínculo entre o currículo (compreendido pelo autor como sistema escolar) e os imperativos sociais, concebidos como uma adaptação ou (re) transformação das bases industriais, visando a sua modernização. Assim, a modernização depende do aumento da produtividade, geração de riqueza, mas também da exigência da formação de uma mão de obra capaz de alimentar este círculo produtivo onde um dos princípios é a compreensão dicotômica saber/não saber, aprovar/reprovar e que tem uma relação direta com o sistema de provas, exames e o sistema de ensino na sua versão mais tradicional.

Com essa perspectiva, nossa sociedade concebe uma relação direta entre sistema de provas, exames e sistema de ensino. Acredita-se que a excelência está ancorada no princípio de que provas e exames são os únicos artifícios capazes de produzir saber, separar quem é inteligente daquele que não é, pois são as provas e os exames que legitimam essa dinâmica social. Percebe-se a urgência de realização de amplos fóruns sobre outras iniciativas de concepção de processos avaliativos para incorporarmos a pluralidade como ideário. As ações e práticas significativas para quem vive a educação escolar não pode ser privilégio de alguns. Quando se adota uma concepção de avaliação baseada em um processo de investigação, de encontro de caminhos pelos quais se pode trabalhar em colaboração via portais distintos para novas aprendizagens, a possibilidade de desconstrução do próprio sentido de avaliar como julgamento deixa de ser utópica.

Trata-se de uma proposta que se assenta em espaços agregadores e dialógicos de oportunidade de pensar e criar outros tantos caminhos que ampliem as habilidades desses sujeitos no sentido de não interrompermos seus processos de busca de sentidos no contato com saberes, também, diversos. Diante da ideia de avaliação como medida, como 
classificação que fixa estudantes como os que sabem e, os que não sabem, o impacto sofrido por ocasião do ingresso em uma instituição universitária para o curso de Pedagogia ganhou relevo.

Ao questionar a cena educacional e os seus mais graves problemas como é o caso da avaliação, Maria Teresa Esteban (2003, p. 7) argumenta que essa última faz parte de um processo mais amplo da discussão sobre o fracasso escolar, principalmente das crianças das classes populares, porque elas convivem cotidianamente com o insucesso na escola. A autora esclarece que, inserido no fracasso escolar estão as "multiplicas negações, dentre as quais se coloca a negação da legitimidade de conhecimentos e formas de vida formulados à margem dos limites socialmente definidos como válidos". O que fica explícito nessa afirmação é que as manifestações dos (as) estudantes, principalmente os (as) das classes populares, não são reconhecidas como legitimas, válidas, porque trazem necessidades, questionamentos e vivências particulares que não se encaixam no que é socialmente aceito, no que é hegemonicamente reconhecido. Portanto, uma grande massa de excluídos é produzida pela escola, na medida em que critérios utilizados para a avaliação do aprendizado não reconhecem as singularidades, as particularidades, as necessidades do diferente.

\section{Avaliação como possibilidade intercultural e colaborativa}

Experimentamos um espaço de formação acadêmica no qual nos deparamos com fóruns diversos sobre os desafios da avaliação da aprendizagem e evidenciamos a presença de um professorado preocupado e em busca de diferentes estratégias para a composição curricular. Portanto, a experiência anterior como graduanda em um curso de Economia se converteu em uma oportunidade de avaliar o ser universitária em segundo curso - dessa vez em uma unidade de formação de professores (as). As oportunidades de trabalhar coletivamente com os pesquisadores e estudantes de cursos diversos de licenciatura em um mesmo universo (os encontros das aulas) é um traço marcante e oferece um novo status para as análises que se seguem sobre como seria aprender e contribuir para re-significar as aprendizagens docentes/discentes. As propostas apresentadas por cada um (a) dos (as) professores (as) das disciplinas cursadas favoreceram uma virada de posicionamento para a ampla maioria dos (as) graduandos (as).

Desenvolver a habilidade da escrita tem sido um investimento na profissão docente e se funda no compromisso assumido com os (as) interlocutores (as) conquistados (as) ao longo da vida universitária. Entretanto, as memórias aqui recuperadas e que incluem o "ser adolescente na escola" impõem desafios tais como lidar com a mudança de lugar social e de 
fortalecimento intelectual. Assim, ao ingressar no curso de Pedagogia, o choque de saber que seria necessário escrever (e bem), com coesão e coerência sobre temas estudados em disciplinas tais como Antropologia e Educação, por exemplo, gerou insegurança. Toda a experiência de fazer os testes, até então, era a de enfrentar as provas objetivas, tentar prestar atenção às pegadinhas embutidas nesses materiais. Para os/as estudantes, eram esses os meios com os quais os (as) professores (as) saberiam o quanto alguém é capaz e está apto para sua promoção. Na universidade, a conversa era outra.

Além de tudo a ser enfrentado, precisaríamos escrever sobre nossas impressões de estudo. Outro monstro a ser combatido! Outro medo a superar! mais nervosismo e insegurança! Na Escola de formação de professores estudamos em diálogo com alguns pares do corpo discente e docente; fomos levados a escrever e a fazer esquemas e estudo de caso. Levados a entender como são as etapas de um projeto político-pedagógico e a importância do núcleo docente estruturante responsável pela proposta curricular. Ensaiar a docência, entre tantos outros exercícios que, a nosso ver, favoreciam novas ambiências de aprendizagem coletiva, deu-nos vantagens acadêmicas, se assim pudermos considerar.

Em certo episódio em que faríamos uma avaliação presencial, soubemos que poderíamos utilizar nossas anotações. O tema da semana nos corredores, nos intervalos para o cafezinho e a sopa, foi esse o assunto. No balcão do setor de fotocópia de material de apoio era evidente a surpresa que marcou aquele período na graduação e que nos levou a indagar sobre:

a) quais concepções estariam em disputa nessa dinâmica avaliativa?

b) Como entender um projeto político-pedagógico onde a autonomia discente passaria a ser vista como um valor?

Sim! Poderíamos utilizar nossos esquemas para fazer a prova! Esta informação não nos trouxe alento. Pelo contrário, já que não estávamos preparados (as) para fazer uma prova naqueles moldes. Após o ritual de passagem, o resultado: tiramos nota 10 (dez)! Mas como "nota 10"? Essa pergunta e o impacto evidenciam toda a insegurança do coletivo dos (as) estudantes com relação ao nosso aprendizado e ao pavor de passar por tais processos, alimentado pelos anos de vida escolar onde o que se aprendeu foi temer qualquer modo de avaliação. No momento seguinte, diante do impacto dos resultados e em uma ação de acolhimento, o professor nos explicou que na atividade realizada conseguimos escrever sobre o conceito de cultura de forma clara e demonstrando autoria. 
Utilizamos adequadamente concepções apresentadas ao longo do período e seus diversos teóricos. Insatisfeitos (as), perguntamos:

Como conseguimos este feito?

A resposta foi que havíamos alcançado esse resultado "lendo, estudando e refletindo coletivamente ao longo do período". Conforme as conversas de corredor que se seguiram:

Interagimos com os (as) autores(as) e suas argumentações...

Tal opção nos fez discutir...

Privilegiou-se o fórum....

Esmiuçamos os conceitos...

Organizamos oficinas temáticas....

Passamos a entender a proposta...

A avaliação não se constituiu em provas ou exames destituídos de sentido.

Apresentamos uma diversidade de análises.

Daí, a crença na potencialidade da concepção diferenciada desse educador e na concepção de avaliação adotada. Ao relermos os trabalhos de Cipriano Luckesi (2000, p. 171) fomos levados a ampliar nossa compreensão sobre as formas de interpretar a avaliação da aprendizagem escolar, já que para o autor ela está diretamente ligada a um ato amoroso, de acolhimento, porque o objetivo desta ação não é a de aprovar/reprovar ou medir a inteligência do estudante. Tem, antes de tudo, a finalidade de auxiliar seu desenvolvimento. Pensar avaliação como ato amoroso pode ser pensá-la como acolhimento, de inclusão de si e do outro, permitindo que o diferente de mim possa ser ele mesmo, possa sentir que não está sendo julgado, tendo em vista que este sentimento pode afastar os estudantes das ambiências propostas para o desenvolvimento das ações. Em outros termos, avaliação para Luckesi (2000, p.171) não é julgar e pode ser uma possibilidade de encontrar brechas de aprendizado de si e do outro, de estimular a relação entre o sujeito e o objeto de conhecimento, mas, principalmente, incluir aqueles que se sentem estrangeiros (as) diante de uma escola que insiste em considerá-los (as) como tal, na medida em que percebe que não se encaixam no modelo padrão. Caberia indagarmos sobre quem é este outro?

Sobre o âmbito escolar, Skliar (2003, p. 39) afirma que o outro não é compreendido porque nós não queremos saber quem ele é. E como consequência o que nós temos feito é "massacrar, assimilar, ignorar, excluir", colocando em prática a concepção de uma avaliação da aprendizagem que classifica. Quando Carlos Skliar discorre sobre inclusão, entende-se que está implícita uma mudança que se traduz no encaixe do outro em um modelo já sedimentado. Assim, a inclusão que tanto se discute e se tenta colocar em prática nas escolas não para de uma burocratização do outro, onde a sua inclusão se baseia em um currículo não adequado a ele ou não pensado para ele, para as necessidades individuais. $\mathrm{O}$ autor argumenta que por traz 
dos ventos da inclusão do outro, do diferente, o que pode ocorrer é que essa burocratização produz o encaixe do outro em uma educação padronizada, limitante. Nesta burocratização do outro pode emergir uma exclusão disfarçada de inclusão, onde o diferente só é lembrado em momentos esporádicos, em determinadas situações.

Sabemos que não é fácil por em prática a concepção mais ampliada da avaliação, sobretudo quando a realidade nos mostra o impasse de professores e professoras diante de um modelo outro de avaliação que considere as singularidades dos (as) estudantes, uma vez que o modelo hegemônico, aquele que confere legitimidade aos resultados apresentados pelos(as) alunos(as), tem como referência a medição.

É aqui que percebemos a força do argumento de Candau sobre a Educação intercultural crítica. Para pensar a avaliação a partir das diferenças, fará mais sentido entender esses pressupostos mais dialógicos e mais colaborativos. Nesse caminho, se quisermos potencializar os processos de aprendizagem na perspectiva da garantia de direitos e de maior justiça, teremos que problematizar questões relativas ao reconhecimento e da valorização das diferenças culturais no contexto escolar (CANDAU, 2012a, p. 237). E se assim for possível, esses aspectos - diferenças culturais - mudam de status e passam a ser indispensáveis, uma vez que se constituem como uma chance de estimularmos a ampliação das possibilidades com os saberes diversos, com o conhecimento sobre si mesmo e sobre as coisas do mundo da vida. Por esses argumentos, a avaliação pode se constituir como elemento de investigação das diferenças culturais que interferem no processo de ensinar e de aprender.

Para essa análise acerca dos impactos que sofremos como estudantes e sobre os riscos da docência não crítica, pensar a avaliação a partir da perspectiva intercultural crítica significa considerar que ela "[...] afeta a educação em todas as suas dimensões, favorecendo uma dinâmica de crítica e autocrítica, valorizando a interação e comunicação recíprocas, entre os diferentes sujeitos e grupos culturais" (CANDAU, 2012b, p. 45). Ao concebermos a avaliação a partir dessa perspectiva poderemos assumir um olhar que se funda no "[...] reconhecimento do direito à diferença e a luta contra todas as formas de discriminação e desigualdade social”, porque essa perspectiva estabelece que a relação professor (a) e estudante se assente em alicerces dialógicos e igualitários, “[...] entre pessoas e grupos que pertencem a universos culturais diferentes, trabalhando os conflitos inerentes a esta realidade" (CANDAU, 2012b, p. 46).

Vislumbramos a alternativa de nos afastar daquilo que Sampaio (2010, p. 2) afirma ser “[...] a concepção classificatória de avaliação, bastante discutida e criticada, [que] ainda é hegemônica nas ações avaliativas realizadas diariamente no cotidiano escolar". Pensando 
interculturalmente, nos mobilizamos para pensar a avaliação de forma dialógica, crítica e autocrítica, o que pode implicar em mudanças provocadoras de discussões sobre as práticas avaliativas.

O argumento abaixo sobre narrativas de professoras e práticas educativas nos orientaram:

O movimento de interrogar a própria prática, no diálogo prática/teoria/prática, [que] permitiu que algumas professoras fossem compreendendo não ter sentido dividir e classificar [alunos e alunas]. Segundo seus saberes e não saberes, pois conhecimentos diferentes circulam na sala de aula (SAMPAIO, 2010, p.5).

Daí, o movimento de discussão e de diálogo que vivenciamos como estudantes e como professoras e também o exercício diário de escrever, de dialogar com a teoria, tem se configurado como suporte para compreendermos o que nos atravessa em termos das experiências diversas com os saberes a serem trabalhados e questionados ao mesmo tempo. São aspectos significativos das práticas avaliativas que influenciam nossa compreensão sobre os jogos de poder que garantem assimetrias já denunciadas nos estudos que recuperamos aqui. Tais aproximações nos levaram ao encontro da abordagem Educação intercultural crítica por acreditarmos em práticas de fortalecimento e de respeito às diferenças. Para o sistema educacional será inevitável rever suas propostas de formação contínua dos (as) educadores (as). E se assim for possível considerar, a universidade passa a ser interlocutora fundamental.

\section{Algumas considerações finais}

Ao optar por um estudo que congregasse a experiência discente e a experiência docente, fez sentido tomar como ponto de partida os episódios vividos em um contexto onde a questão da diferença, da singularidade e da alteridade nunca foram consideradas ou sequer discutidas. Por isso, vimos como imprescindível sugerir e defender outras possibilidades de aprender/ensinar no processo de formação docente. E pensar amplos caminhos, encontrar alternativas, dialogar sobre mais sobre os efeitos e menos sobre os resultados. Conceber o cotidiano na sua totalidade significa ir além da sala de aula onde atuamos. Acredita-se que conhecer os grupos com os quais a instituição educadora constrói seus espaços de aprendizagem - muitas vezes também para além dos seus muros -, acompanhar suas experiências cotidianas, lidar com as diferenças que habitam esse cotidiano pode dar sentido à nossa intervenção como sujeitos que atuam na perspectiva de uma educação emancipatória. 
Por isso, faz diferença entender os avanços e os ranços do debate acerca das práticas, das mediações didáticas que podemos adotar nesse ir e vir entre escola e universidade.

Para avançarmos nas propostas de reinvenção das ambiências de aprendizagem será importante assumirmos alguns riscos tais como admitir o quanto não incorporamos a realidade dos sujeitos com os quais trabalhamos na formação para a docência. Seus interesses são diversos. O trabalho no cotidiano escolar e o acompanhamento das concepções que interferem nas representações construídas pelas (os) professoras (es) sobre os sentidos da avaliação, nos mostram que o entendimento de que avaliar é classificar ainda vigora. Essa concepção, que nos impregna e nos constitui, impede que as singularidades se evidenciem além de apontar para um enquadramento dos (as) alunos (as) em um modelo já posto, a partir da burocratização do processo. Esse desconhecimento das experiências está refletido nos espaços das instituições que interrompem processos criativos. Embaçam a liberdade de pensar, e, por conseguinte, o desenvolvimento de um conjunto de potencialidades.

A rotina de provas, testes e exames que se anuncia a cada retorno às aulas, é o calvário de todo estudante. Afinal, o que ainda está internalizado em nós é que na escola, se estuda para a realização das provas e, estas, tem o objetivo de classificar, de excluir, de registrar o que sabemos. Por outra parte, na medida em que refletimos sobre a avaliação não como forma estanque de medir conhecimentos podemos perceber as possibilidades de vivenciar práticas avaliativas que extrapolam a concepção burocrática e hegemônica de medir a aprendizagem. São oportunidades de criar amplas saídas práticas, na medida em que ressignificamos o nosso conceito sobre avaliação do ensinoaprendizagemensino ${ }^{i i}$. O que defendemos são modos alternativos de avaliação que possam valorizar os conhecimentos de mundo que habitam os sujeitos do espaço educacional, além de estimularem o confronto das subjetividades, com aquilo que ainda não conhecemos.

Para isso, vimos como necessário partimos de reinvenções dos modos de avaliar. Considerar a desconstrução de concepções excludentes que nos habitam. E a perspectiva intercultural crítica se apresenta como uma concepção de educação emancipatória calcada no diálogo entre as diferentes culturas que constituem nossas experiências interacionais e que se dão na escola e fora dela. Vimos uma oportunidade de realizarmos a autocrítica para avançar ampliando nossos olhares acerca do papel da educação no processo de superação das desigualdades. E nesse espaço de reflexão partimos de nossas experiências discentes/docentes com a avaliação visando contribuir com as práticas educativas adotadas nos espaços escolares. 
A escuta sensível para com as iniciativas em curso tem sido uma tática de fortalecimento dessas concepções aqui em destaque. De certo, podemos afirmar que estamos no movimento de pesquisar, de encontrar modos de dialogar com as diferenças, de pensar com as teorias, mas também com as práticas que fundamentam as nossas ações e nos ajudem a compreender as urgências. Acreditamos em práticas dialógicas, no conhecimento do outro, na realidade multicultural para enfrentar desafios impostos pela pluralidade de sujeitos e de culturas. Trabalhar e defender práticas interculturais passa a ser uma estratégia, na adoção de um eixo norteador das nossas intervenções como educadoras. Acreditamos que as diferenças que desafiam a escola apontam para uma visão mais abrangente de avaliação e que as perguntas tem o poder de nos deslocar e de nos apresentar outros atalhos para avançarmos nas desconstruções urgentes do que se tornou natural. Interrompemos estas considerações com uma afirmativa por acreditarmos que, em movimento, em constante processo de reflexão é que garantiremos interseções fundamentais sobre o sentido das nossas experiências discentes/docentes.

\section{Referências Bibliográficas}

BARRIGA Ángel Diaz. Avaliação: uma pratica em busca de novos sentidos. In: Avaliação: uma pratica em busca de novos sentidos. Maria Teresa Esteban (org.). - 5. ed. - Rio de Janeiro: DP\&A, 2003.

CANDAU, Vera Maria Ferrão. Diferenças culturais, interculturalidade e educação em direitos humanos. Educação \& Sociedade, Campinas, v. 33, n. 118, p. 235-250, jan.-mar. 2012a. Disponível em http://www.cedes.unicamp.br acesso em 20-03-14

Rio de Janeiro: Vozes, 2012b.

(Org.). Didática crítica intercultural: aproximações. Petrópolis,

ESTEBAN, Maria Teresa. Avaliação no cotidiano escolar. In: Avaliação: uma pratica em busca de novos sentidos. Maria Teresa Esteban (org.). - 5. ed. - Rio de Janeiro: DP\&A, 2003.

LUCKESI, Cipriano Carlos. Avaliação da Aprendizagem Escolar: um ato amoroso. In: Avaliação da Aprendizagem Escolar: estudos e proposições. 10 ed. - São Paulo: Cortez, 2000. SAMPAIO, Carmen Sanches. Relações de aprendizagem (e ensino) na escola de Ensino Fundamental: (In)temporalidades da participação na avaliação pedagógica. In: ESTEBAN, Maria Teresa \& Afonso, Almerindo Janela (orgs). Olhares e interfaces - reflexão sobre a avaliação. São Paulo, Cortez, 2010, p. 01-20.

SKLIAR, Carlos. A educação e a pergunta pelos Outros: diferença, alteridade, diversidade e os outros “outros". Ponto de Vista, Florianópolis, n.05, p. 37-49, 2003.

Disponível em:< http://www.perspectiva.ufsc.br/pontodevista_05/03_skliar.pdf $>$ acesso em $09 / 10 / 12$

\footnotetext{
i Mestranda em Educação, pela Universidade Federal do Estado do Rio de Janeiro (UNIRIO)
} 


\begin{abstract}
ii Ensinando, aprende-se", frase cunhada pelo Filósofo Sêneca ilustra o termo ensinoaprendizagemensino, por compreendermos que é ensinando que se aprende a ensinar. Ensinar e aprender se complementam, são ações interdependentes, pois acreditamos que não há ensino sem aprendizagem, assim como também não há aprendizagem sem ensino.
\end{abstract}

